\title{
Preclinical development of human granulocyte-macrophage colony-stimulating factor-transfected melanoma cell vaccine using established canine cell lines and normal dogs
}

\author{
G. S. Hogge, ${ }^{1}$ J. K. Burkholder, ${ }^{2}$ J. Culp, ${ }^{2}$ M. R. Albertini, ${ }^{3}$ R. R. Dubielzig, ${ }^{1}$ N.-S. Yang, ${ }^{3}$ and \\ E. G. MacEwen ${ }^{1,3}$ \\ ${ }^{1}$ School of Veterinary Medicine, University of Wisconsin, Madison, Wisconsin 53706; ${ }^{2}$ PowderJect Vaccines, \\ Inc., Madison, Wisconsin 53711; and ${ }^{3}$ University of Wisconsin Comprehensive Cancer Center, Madison, \\ Wisconsin 53792.
}

\begin{abstract}
Tumor vaccines and gene therapy have received significant attention as means of increasing cellular and humoral immune responses to cancer. We conducted a pilot study of seven research dogs to determine whether intradermal injection of canine tumor cells transfected via the Accell particle-mediated gene transfer device with the cDNA for human granulocyte-macrophage colony-stimulating factor (hGM-CSF) would generate biologically relevant levels of protein and result in demonstrable histological changes at sites of vaccination. Tumor cell vaccines of $10^{7}$ irradiated canine melanoma cells were nontoxic, safe, and well tolerated. No significant alterations in blood chemistry values or hematological profiles were detected. A histological review of control vaccine sites revealed inflammatory responses predominated by eosinophils, whereas vaccine sites with hGM-CSF-transfected tumor cells had an influx of neutrophils and macrophages. Enzyme-linked immunosorbent assays of skin biopsies from vaccine sites had local hGM-CSF production (8.68-16.82 ng/site of injection) at 24 hours after injection and detectable levels $(0.014-0.081$ $\mathrm{ng} /$ site) for $\leq 2$ weeks following vaccination. Flow cytometric analysis of hGM-CSF-transfected cells demonstrated $\leq 25 \%$ transfection efficiency, and hGM-CSF levels obtained during time-course assays demonstrated biologically relevant levels for both irradiated and nonirradiated samples. These data demonstrate the in vivo biological activity of irradiated hGM-CSF-transfected canine tumor cells and help provide evidence for a valid translational research model of spontaneous tumors.
\end{abstract}

Key words: Accell; tumor cell vaccine; immunotherapy; melanoma; dog; granulocyte-macrophage colony-stimulating factor.

$\mathrm{I}^{\mathrm{n}}$ mmunotherapy using both nonspecific stimulation and the specific administration of cells or secreted products has gained recognition for its potential usefulness in diseases that are resistant to traditional therapy. The potential benefits of using irradiated tumor cell vaccines to stimulate potent, long-lasting, and specific immunity have been documented in several human and animal trials. ${ }^{1-6}$ Some of these trials used cytokines to increase tumor antigen (Ag) recognition and cytolytic activity against specific tumor-associated Ags., 1-11 However, a systemic administration of cytokines is associated with significant toxicity and requires frequent administration of the cytokine attributable to short half lives in vivo. ${ }^{12-15}$ A cytokine-producing tumor vaccine may circumvent these difficulties, as cytokine-gene-engineered vaccines can provide local, prolonged production of immuno-

Received October 25, 1998; accepted May 15, 1998.

Address correspondence and reprint requests to: Dr. E. Gregory MacEwen, University of Wisconsin-Madison SVM, 2015 Linden Drive West, Madison, WI 53706. E-mail address: Macewen@svm.vetmed.wisc.edu

(C) 1999 Stockton Press 0929-1903/99/\$12.00/+0 modulatory protein products, resulting in potential hostmediated antitumor activity. $3,16-19$

Accell (PowderJect Vaccines, Madison, Wis) particlemediated gene transfer uses cDNA-coated gold beads bombarded directly into cells or tissue via specifically targeted, high-pressure, helium pulses; several studies have been conducted to demonstrate the speed and efficacy of this method of mechanical gene transfer. ${ }^{20-25}$ Stable, reproducible, and high levels of expression have been obtained using a wide variety of cDNAs, tissues, cell types, and species. ${ }^{26-30}$ Dual expression of separate plasmid vectors within the same cell has been demonstrated. ${ }^{31}$ Protective immunity to several viral diseases has been obtained following Accell delivery of genes encoding viral proteins, ${ }^{32-37}$ and antitumor effects in animals have been observed using specific cytokine genes. $7,9,28,29$

Granulocyte macrophage-colony stimulating factor (GM-CSF) is a pluripotent, naturally occurring growth factor produced by T cells, B cells, macrophages $(\mathrm{M} \phi)$, mast cells, endothelial cells, and fibroblasts in response to different immune or inflammatory stimuli. ${ }^{38,39}$ Clinical applications of GM-CSF include ameliorating che- 
motherapy-associated neutropenia as well as enhancing hematopoietic recovery after bone marrow transplantation. ${ }^{40-42}$ GM-CSF can activate neutrophils, eosinophils, and $\mathrm{M} \phi$ to lyse tumor cells directly or to mediate antibody-dependent cellular cytotoxicity. ${ }^{38,39,43-45}$ It can also increase major histocompatability complex expression of tumor $\mathrm{Ag}$ to immune effector cells, because GM-CSF is important in the maturation and function of bone marrow-derived dendritic cells. These dendritic cells are believed to be professional Ag-presenting cells capable of presenting $\mathrm{Ag}$ to unprimed $\mathrm{CD} 4^{+}$as well as CD8 ${ }^{+}$T cells. ${ }^{46-48}$

Following administration either systemically or in a vaccine fashion, GM-CSF can induce antitumor immunity in many model systems, including the nonimmunogenic F10 variant of B16 melanoma. ${ }^{1,74}$ Additional research has compared the ability of 22 different molecules to stimulate systemic antitumor immunity, and GM-CSF was shown to be the most effective. ${ }^{50}$ Our research group has demonstrated previously the effects of hGM-CSF when administered to dogs either in the context of Accell in vivo transfection into normal skin and oral mucosa or direct subcutaneous administration of the functional hGM-CSF protein. ${ }^{27,51}$ Direct bombardment resulted in functional protein production and local histopathological changes associated with hGMCSF. When administered subcutaneously, blood monocyte and lymphocyte numbers increased, and monocyte antitumor cytostasis activity was enhanced. This current study addresses the administration of hGM-CSF in the context of ex vivo cytokine-gene-engineered tumor cells. Finally, GM-CSF enhances the function of differentiated cells, prolongs the survival of mature neutrophils and eosinophils, and is thought to enhance the ability of cells to respond to secondary stimuli, resulting in increased superoxide production, leukotriene synthesis, and arachidonic acid release. The consequence of these actions is to increase the phagocytic capabilities of relevant cell populations. ${ }^{39}$

Melanomas in dogs provide a translational research model, as cutaneous and oral melanomas are the fourth most common cancer in dogs. ${ }^{52,53}$ Mucosal melanomas are highly metastatic and have a poor prognosis in the higher grades and stages. ${ }^{54,55}$ As is the case for advanced melanoma in humans, melanoma in dogs is generally resistant to chemotherapy and radiation therapy, and metastasis is the major cause of treatment failure and death. ${ }^{56-58}$ Finally, the dog offers a good translational model because of its large size, spontaneous development of tumors, rapid assessment of therapeutic activity, and biological similarity to humans..$^{59,60}$

Based on these data, we initiated preclinical studies in normal dogs using an established canine melanoma cell line, CML-6M. Tumor cells were irradiated, Accelltransfected with hGM-CSF, $\beta$-galactosidase ( $\beta$-gal), or nontransfected, and administered intradermally (i.d.). In addition, canine cell lines were transfected in vitro, and the effects of cytokine or control cDNA were studied in reporter gene assays, flow cytometric analysis, and time course studies. The speed of vaccine creation, ease of vaccine administration, and demonstrated biological effects of hGM-CSF-transfected tumor cells demonstrate the potential clinical applications of these techniques in cancer immunotherapy.

\section{MATERIALS AND METHODS}

\section{hGM-CSF and reporter gene constructs}

The hGM-CSF plasmid constructs have been described previously. ${ }^{7,61}$ The reporter gene constructs pCMV-b and pCMVluc were driven by the cytomegalovirus immediate-early gene enhancer/promoter in a pNASS vector. Plasmids were grown in DH5a Escherichia coli and purified using Qiagen columns (Qiagen, Chatsworth, Calif). Purified DNA was further treated to eliminate endotoxin contamination. ${ }^{62}$

\section{Preparation of gold beads}

Following the methods reported previously, ${ }^{21,63}$ a mixture of $175 \mu \mathrm{g}$ of cDNA and $70 \mathrm{mg}$ of gold particles in $250 \mu \mathrm{L}$ of 0.05 M spermidine (catalog no. S-0266, Sigma, St. Louis, Mo) was added to $250 \mu \mathrm{L}$ of $10 \% \mathrm{CaCl}_{2}$. The cDNA/gold particle precipitates were washed several times with $100 \%$ ethanol and resuspended at a density of $1 \mathrm{mg}$ particles/mL ethanol; next, $100 \mu \mathrm{L}$ of polyvinylpyrrodine was added, and the slurry was allowed to deposit evenly on the lumen of tefzel plastic cartridges and dried with nitrogen. These conditions result in a delivery of $0.5 \mathrm{mg}$ of gold and $1.25 \mu \mathrm{g}$ of DNA per transfection. Tubes were stored desiccated at $-20^{\circ} \mathrm{C}$ until time of use.

\section{Cell lines}

Two adherent canine melanoma cell lines (CML-6M and CML-1), originally established from primary melanoma tumor samples (kindly provided by Dr. Lauren Wolfe, Auburn University, Auburn, Ala), were used for the procedures ${ }^{64}$ Growth media consisted of Leibovitz's L-15 medium (catalog no. 11415-023, Life Technologies, Grand Island, NY) with $10 \%$ fetal bovine serum (FBS), $2 \mathrm{mM}$ L-glutamine, $1 \mathrm{mM}$ sodium pyruvate, $10 \mathrm{mM} N$-2-hydroxyethylpiperazine- $N^{\prime}$-2-ethanesulfonic acid (HEPES), and 1\% penicillin-streptomycin-fungizone. Cells were grown to confluent monolayers in standard plastic flasks at $37^{\circ} \mathrm{C}$ in humidified $5 \% \mathrm{CO}_{2}$ and passaged when necessary. Only cells of $<25$ passages were used in the assays.

\section{3-(4,5-dimethylthiazol-2-yl)-2,5-diphenyltetrazolium bromide (MTT) and clonogenic assays}

To determine which canine melanoma cell line would be used for the vaccine studies, two canine melanoma cell lines were grown in culture, trypsinized, washed, and counted. A total of 10,000 cells in $200 \mu \mathrm{L}$ of growth media were plated per well into 96-well, flat-bottom plates in replicates of five per radiation treatment dose $(1,2.5,5,7.5,10,30,50,75$, and $100 \mathrm{~Gy})$ and incubated at $37^{\circ} \mathrm{C}$ in humidified $5 \% \mathrm{CO}_{2}$. One plate from each cell line was sera-starved $(0 \%$ FBS) for 24 hours to synchronize the cell populations, whereas the others were allowed to continue growing in standard growth media. ${ }^{65,66}$ After 4 days of incubation, $50 \mu \mathrm{L}$ of $2 \mathrm{mg} / \mathrm{mL}$ MTT (Sigma) was added to each well and incubated for 4 hours at $37^{\circ} \mathrm{C}$; all supernatant was aspirated. A total of $100 \mu \mathrm{L}$ of dimethylsulfoxide was added to each well and shaken, and optical absorbance was read at $570 \mathrm{~nm} .^{67,68}$

Clonogenic assays were conducted by irradiating the two lines at the same doses and plating onto $100-\mathrm{mm}$ dishes 
(Falcon 1001, Lincoln Park, NJ). Colonies were counted after 2 weeks of incubation and staining with $10 \%$ crystal violet. ${ }^{69}$

\section{Preparation of target plates for Accell transfection}

Cells were trypsinized from confluent flasks, washed with the growth media described above, centrifuged at 1000 revolutions per minute for 5 minutes, counted by trypan blue exclusion, and resuspended in $10 \mathrm{~mL}$ of media. Samples used in vaccination were irradiated at 100 Gy with a Cesium-137 radiation source under fully oxygenated conditions. All cells were centrifuged and resuspended at $1 \times 10^{6}$ cells per $20 \mu \mathrm{L}$ of media and HEPES buffer. These cells were then spread out to a $1.5-\mathrm{cm}$ circle on the sterile target plate and transfected with the Accell device at 250 pounds per square inch (psi) using either hGM-CSF or $\beta$-gal. These Accell transfection conditions have been reported in numerous papers as being the most effective for a wide variety of cell types, and we confirmed this finding in the dog system through dose-response assays using the reporter gene luciferase. ${ }^{23,70,71}$ Cells were then collected from the target plates using repeated media rinses and cell scrapers and pooled based on treatment in preparation for vaccination. Cell viability was usually $>90 \%$ as determined by trypan blue exclusion.

\section{Luciferase detection}

Cells were transfected as described above, and luciferase activity detected as reported previously ${ }^{20}$ with the following minor noted modifications. Briefly, $200 \mu \mathrm{L}$ of extraction buffer (potassium phosphate, protease-free bovine serum albumin (BSA), phenylmethylsulfonylfluoride, and dithiothreitol) was added to the transfected and washed cells following 12-24 hours of incubation. A total of $1 \mu \mathrm{L}$ was then added to $80 \mu \mathrm{L}$ of $5 \times$ reaction buffer (glycylglycine ( $\mathrm{pH} 7.8$ ), $\mathrm{MgCl}_{2}, \mathrm{BSA}$, and adenosine 5 '-triphosphate) and $119 \mu \mathrm{L}$ of distilled water. The samples were vortexed, and $300 \mu \mathrm{L}$ of luciferin solution was added (luciferin, distilled water, and $\mathrm{NaHCO}_{3}$ ) before analysis. Light emittance was measured using a Berthold Lumat LB9501 luminometer (EG\&G Berthold, Wellesley, Mass).

\section{Flow cytometry staining}

Intracellular cytokine staining involves initial fixation of cells in paraformaldehyde to cross-link proteins and prevent their leakage. The cellular membranes are permeabilized with a mild detergent, generating gaps that allow fluorochromeconjugated monoclonal antibodies access to the cell interior. The resulting labeled cells are indicative of cytokine production, allowing the classification of individual cells according to their cytokine production pattern. Intensity of staining is proportional to Ag content. Protocol for hGM-CSF staining was as follows: cell suspensions were washed twice in balanced salt solution (BSS) with $0.01 \%$ HEPES buffer, $1 \%$ FBS, and $0.1 \%$ sodium azide before fixing with $500 \mu \mathrm{L}$ of $4 \%$ paraformaldehyde, which was allowed to incubate for 10 minutes. Next, cells were washed twice in BSS containing 0.005\% saponin to permeabilize the cell membranes. Alternative permeabilization with Permafix (catalog no. 77599, Ortho Diagnostic Systems, Raritan, NJ) involved adding $2 \mathrm{~mL}$ of Permafix to $100 \mu \mathrm{L}$ of $1 \times 10^{6}$ cells and incubating at room temperature for 1 hour. Biotinylated antibody (catalog no. 11022C (biotin rat $\mathrm{IgG} 2 \mathrm{~A}^{\mathrm{K}}$ for isotype control) or catalog no. 185920 (antihGM-CSF), both from PharMingen, San Diego, Calif) was added to 250,000 cells in $100 \mu \mathrm{L}$ of BSS-saponin and allowed to incubate at room temperature for 45 minutes. Samples were washed twice in BSS-saponin and subsequently incubated with streptavidin-conjugated phycoerythrin $\left(\sim 0.5 \mu \mathrm{g} / 1 \times 10^{6}\right.$ cells $)$ for 30 minutes at room temperature followed by two washes in BSS-saponin. Vimentin (catalog no. 1112-457, Boehringer Mannheim, Indianapolis, Ind) was used to demonstrate membrane permeabilization. Samples were stored dark and were refrigerated until analysis. All samples were analyzed using a Becton Dickinson FACScan flow cytometer (Mountain View, Calif), and data were processed using the WINMDI software program (The Scripps Research Institute, La Jolla, Calif).

\section{Animals and assessment of treatment responses}

A total of seven, normal, healthy beagle or hound crosses (ranging in age from 3 to 6 years) were used. All dogs were heartworm negative, free of ectoparasites and endoparasites, and housed in an American Association for the Accreditation of Laboratory Animal Care-approved vivarium. All animals were subjectively evaluated before treatment and daily during treatment for changes in eating or drinking and for behavioral changes related to pain or toxicity. Objective measurements included temperature, pulse, respiration, and body weight. Complete blood counts, blood chemistry panels, sera samples, and skin biopsies at the sites of vaccination were taken in accordance with the established protocol schema described above. Biopsy samples were split in half with a No. 10 scalpel blade; half were placed into formalin for histological analysis, whereas the remaining half were placed into $300 \mu \mathrm{L}$ of general extraction buffer containing Pefablock (Boehringer Mannheim), phosphate-buffered saline (PBS), $10 \%$ Triton X-100, BSA, and dithiothreitol for future hGM-CSF enzyme-linked immunosorbent assay (ELISA). ELISA samples were stored frozen at $-80^{\circ} \mathrm{C}$ until the time of analysis. Biopsy sites were closed using 3-0 nylon in simple cruciate patterns. All protocols and procedures were approved by the University of Wisconsin Research Animal Resource Center.

\section{Vaccine preparation and vaccination procedure}

Transfected and control nontransfected cells were washed with PBS and concentrated to $1 \times 10^{7}$ cells per $100 \mu \mathrm{L}$. Recipient animals were sedated with ketamine $(5 \mathrm{mg} / \mathrm{kg})$ and valium $(0.5$ $\mathrm{mg} / \mathrm{kg}$ ) and shaved on the flank around the area of vaccination to facilitate easier assessment of local reaction; next, i.d. injections with a 27 -gauge needle in a $1-\mathrm{mL}$ tuberculin syringe were made.

The initial aspect of this study involved four dogs: two were given a dose of $10^{7} \mathrm{hGM}$-CSF-transfected, irradiated, CML-6M tumor cells administered i.d. in two sites in the thoracic region; another two dogs were vaccinated in two sites with $10^{7}$ control nontransfected, 100 Gy-irradiated, CML-6M cells. Vaccination sites were biopsied on days 1 and 7. A second vaccination $\left(10^{7}\right.$ cells, one site $)$ was performed on day 14 and biopsied on day 28. Complete blood counts, sera chemistry panels, single-blinded histopathological review, and hGM-CSF ELISAs were conducted at days 1, 7, and 28.

The second aspect of this study used three normal dogs inoculated with $10^{7}$ hGM-CSF-transfected, $100 \mathrm{~Gy}$-irradiated cells in two i.d. sites on the right side and inoculated with $10^{7}$ $\beta$-gal-transfected, irradiated cells in two i.d. sites on the left side. Skin biopsy samples were taken on days 1 and 7. The animals were revaccinated on day 7 with $10^{7}$ cells (one site each for hGM-CSF- or $\beta$-gal-transfected cells) and were treated as described above. Biopsies were obtained on day 21, and ELISAs and histopathological review were performed. 


\section{Time course assays}

The two canine melanoma cell lines were transfected in triplicate in suspension using six-well plates (Falcon 3046) $(1 \times$ $10^{6} /$ well), as described above. Supernatant samples were collected in both independent and cumulative fashions in 12-hour increments. Independent timepoint samples had $2 \mathrm{~mL}$ of fresh growth media added at each timepoint. Protein levels of hGM-CSF in the supernatant were determined using ELISA.

\section{ELISA methods}

Levels of hGM-CSF for the time course experiments were determined using rat anti-hGM-CSF (catalog no. 18581D, PharMingen), biotin rat anti-hGM-CSF (PharMingen, 18592D), streptavidin-horseradish peroxidase conjugate (catalog no. 43-4323, Zymed, San Francisco, Calif), and tetramethylbenzidine substrate (S1600, Dako, Carpinteria, CA). Sensitivity using plates prepared in this manner was $56 \mathrm{pg} / \mathrm{mL}$. $^{7}$ The samples tested were $1 \mathrm{~mL}$ of media taken at various timepoints. Cell lysates were obtained using $250 \mu \mathrm{L}$ of general extraction buffer at the same timepoints.

Commercial hGM-CSF ELISA kits (catalog no. KHC2012, Biosource, Camarillo, Calif) were used to assay all biopsy and sera samples because of increased sensitivity $(10 \mathrm{pg} / \mathrm{mL})$. Biopsy samples were minced and brought to $1-\mathrm{mL}$ volumes with PBS. The standard kit protocol was followed for all samples and assayed in duplicate. Canine GM-CSF does not cross-react in either assay. ${ }^{27}$

\section{Histopathology}

Punch biopsy samples were placed in $10 \%$ formalin until routine processing. Samples were blocked in paraffin, cut into $5-\mu \mathrm{m}$ sections, and stained with hematoxylin and eosin. All samples were interpreted by a veterinary pathologist (R.R.D.) who was blinded to treatment. In an effort to quantitate the inflammatory responses, an objective determination of the greatest area of inflammatory or liquifactive necrosis was calculated through microscopy by measuring the largest areas of visible cell destruction (also in a single-blinded fashion).

\section{Statistical methods}

Protein expression levels for control- and hGM-CSF-transfected cells (for both in vitro and in vivo samples) as well as cell proliferation responses were all assessed using the repeated measures test. A $P$ value of $<.05$ was considered significant.

\section{RESULTS}

Optimization of Accell transfection in canine cell lines

Two established canine lines, CML-1 and CML-6M, were transfected with luciferase cDNA and assayed for luciferase expression after 24 hours. The expression levels of the two cell lines at differing psi is shown (Fig 1). Different DNA loading doses were also studied, and little difference was observed using all standard bead preparation dose levels. It is interesting to note the differences in expression between the highly metastatic line CML-6M and the nonmetastatic line CML- $1 .{ }^{64} \mathrm{We}$ are attempting to determine whether this trend of increased expression in highly metastatic cells holds true in other canine cell lines and primary tumor samples.

\section{Luciferase expression}

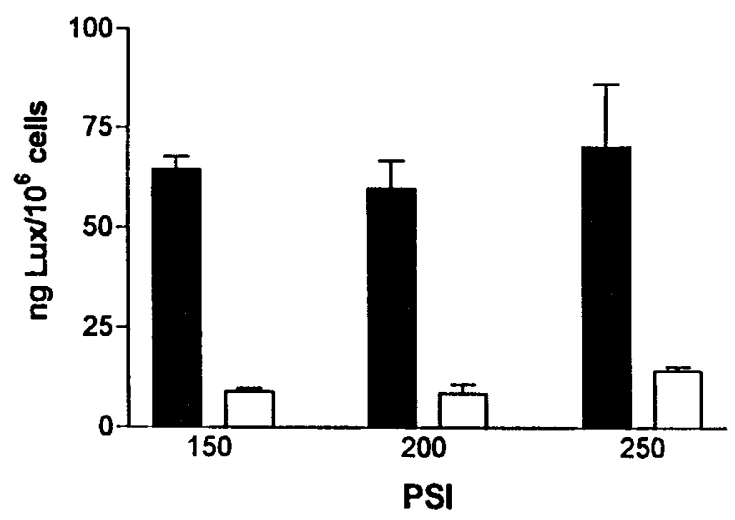

Figure 1. Luciferase optimization of Accell transfection for canine cell lines. The expression of luciferase for the two canine melanoma cell lines (transfected as described in Materials and Methods with luciferase cDNA-coated gold beads) is shown. Expression levels were obtained for $1 \times 10^{6}$ cells in a 24-hour period and are expressed as the mean and SEM from triplicates in independent trials. Higher psi of helium resulted in an increased loss of cell viability, with no increase in expression level. Results for CML-6M, the highly metastatic line, are represented by filled bars; results for CML- 1 are represented by open bars.

\section{Flow cytometry demonstrates hGM-CSF protein production in canine cells}

To demonstrate a biological production of hGM-CSF protein product following Accell transfection, CML-6M and CML-1 canine melanoma cell lines were transfected and examined by intracellular cytokine staining. Vimentin was used as a positive control and demonstrated permeabilization of the cellular membranes using either method (Fig 2a). Luciferase or $\beta$-gal reporter genetransfected cells were compared with hGM-CSF-transfected cells to demonstrate that the process of particle bombardment alone did not result in peak shifts and to determine the percentage of cells staining positive for hGM-CSF (Fig 2b). The viability and integrity of the hGM-CSF-transfected cells were comparable with the control-transfected population. Similar results were obtained using both techniques of permeabilization. Transfection efficiencies of between $10 \%$ and $25 \%$ were observed in the canine cell lines. hGM-CSF staining of the control-transfected canine cells alone did not result in nonspecific binding, although the process of transfection and gold bead penetration does result in an alteration of autofluorescence compared with the isotype control.

\section{Irradiation of canine cells induces reproductive cell death while maintaining protein production}

MTT proliferation and clonogenic assays were used to study reproductive cell death following irradiation. Melanoma cells (CML-1 and CML-6M) were exposed to various radiation doses (0-100 Gy) using a Cesium-137 radiation source. Clonogenic assays were incubated for 2 

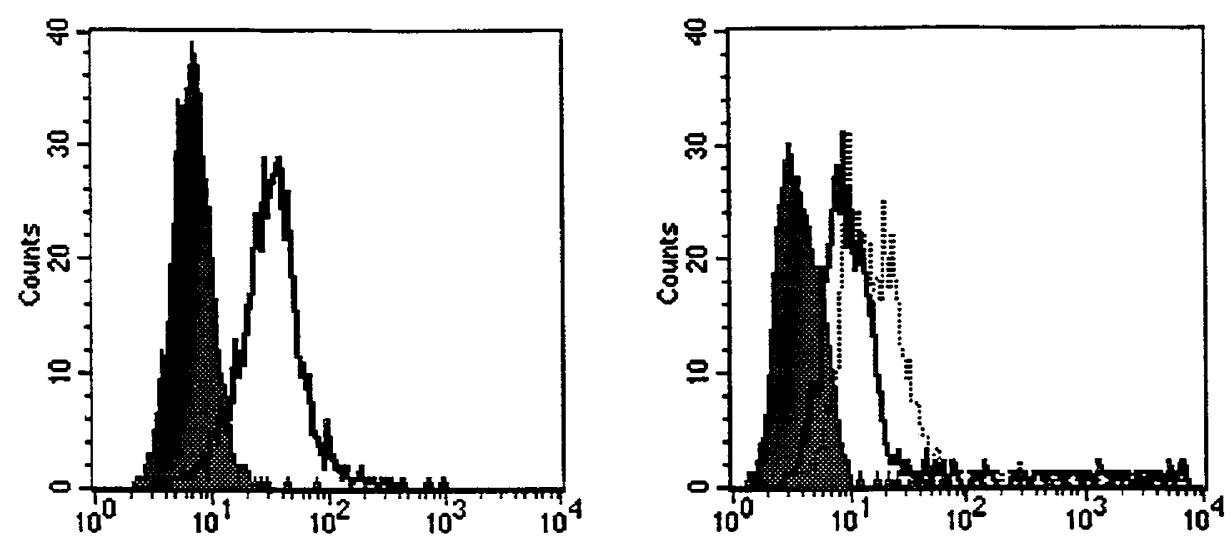

Figure 2. Flow cytometric analysis of canine melanoma cells. a: CML-6M cells were permeabilized and stained for vimentin (open peak) or IgG2A isotype control (filled peak) to demonstrate membrane permeabilization. b: CML-6M cells transfected with hGM-CSF (hatched line), control-transfected (solid line), or isotype control (filled peak) were permeabilized as described previously, stained for hGM-CSF, and analyzed for percent transfection. A transfection efficiency of 10-25\% hGM-CSF-positive cells was observed in the canine cell lines using Accell compared with the control-transfected cells. The viability and integrity of the transfected cells were comparable with the control population.

weeks, and colonies were counted by staining with crystal violet. No colonies were observed at any radiation levels of $>10$ Gy (data not shown). The MTT assays revealed significant proliferative reductions at $>5$ Gy for the CML-1 line and at 10 Gy for the CML-6M line (Fig 3). Similar results were seen with both sera-starved samples as well. Taken together, these data demonstrate that the radiation dose of 100 Gy that was administered is sufficient to arrest cell growth while permitting the safe, biologically active administration of genetically modified canine tumor cells.

\section{Proliferation inhibition for various radiation doses}

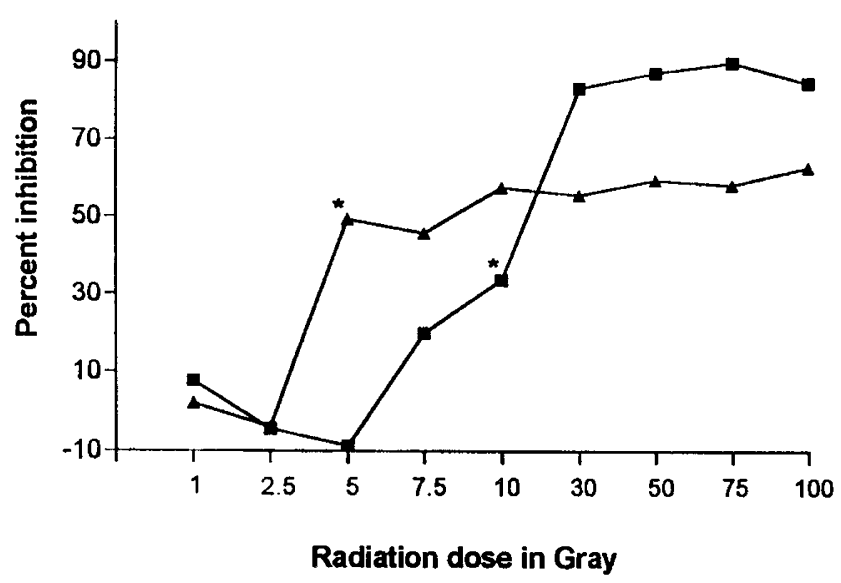

Figure 3. MTT cell proliferation assay of irradiated canine melanoma cells. A total of 10,000 canine melanoma cell lines were plated in 96-well plates in replicates of five per radiation treatment dose and allowed to incubate for 4 days before the addition of $2 \mathrm{mg} / \mathrm{mL}$ MTT. Dimethylsulfoxide was added to lyse cells, and optical absorbance

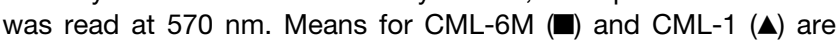
shown. Synchronized cells through sera starvation showed similar results. * indicates significance $(P<.05)$
Canine melanoma cell lines express high levels of hGM-CSF as detected by ELISA during time course assays

CML-6M and CML-1 cells were transfected as described previously, and supernatant samples from separate cultures were obtained at indicated timepoints. hGM-CSF protein expression was quantified (ng/ $10^{6}$ cells/timepoint) for both lines using ELISA (Fig 4). Importantly, total hGM-CSF protein expression was similar for both irradiated and nonirradiated cells. It is our experience that canine cells transfect and express well using the Accell gene delivery device and human cytomegalovirus promoters. Transfection efficiency and expression was highest in the CML-6M line. This observation, in combination with the luciferase and flow cytometric analyses, led us to decide that this line should be used for our ex vivo vaccine protocol in normal dogs.

Ex vivo vaccines produce noticeable inflammatory responses compared with controls

At 24 hours, mild induration, erythema, and pruritus at sites of hGM-CSF-transfected tumor cell injection were noted. All were mild and within acceptable limits. These responses were noticeably greater than those observed at sites injected with the control- or $\beta$-gal-transfected cells. It was difficult to locate control samples for the third biopsy (days 21 or 28), because the inflammatory response was very mild, with little evidence of an eschar. However, hGM-CSF-transfected samples were more easily located at all timepoints because of the presence of eschars and a continued mild inflammatory response.

Histopathological evaluation of the hGM-CSF-transfected cell injection sites demonstrated prominent neutrophilic infiltrate, lymphocytes, and $\mathrm{M} \phi$ adjacent to the tumor cells and spreading beyond the dermis into the subcutaneous tissue. Disruption of collagen bundles, follicular atrophy, and a diffuse inflammatory necrosis 


\section{Canine melanoma cell lines transfected with hGM-CSF}

Figure 4. Time course assay for hGMCSF-transfected canine melanoma cells. CML-6M and CML- 1 cells were transfected as described previously, and supernatant was collected from separate cultures at $12,24,36,48,60$, and 72 hours in a cumulative fashion for both irradiated and nonirradiated samples of each line. Thus, the 12-hour samples represent hGM-CSF production accumulated over 12 hours, 24-hour samples represent accumulation over 24 hours, and so forth. ELISAs were conducted as described previously. CML-6M (stippled bars, nonirradiated; open bars, irradiated) proved to be a significantly higher expresser of hGM-CSF than did CML-1 (filled bars, nonirradiated; cross-hatched bars, irradiated); * indicates significance $(P<.05)$.

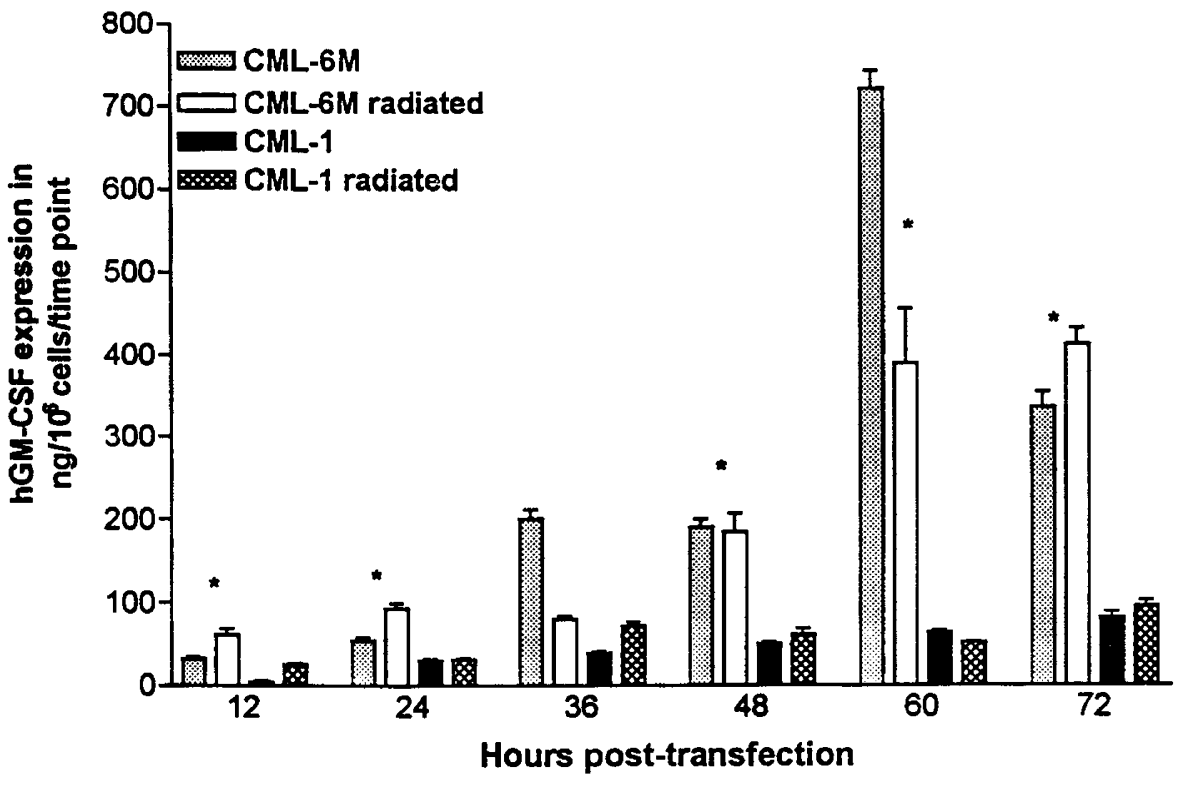

were also evident by day 7. In contrast, the control $\beta$-gal-transfected or nontransfected samples revealed moderate eosinophilic infiltrate and minimal neutrophil and $\mathrm{M} \phi$ infiltration away from the site of injection. Furthermore, collagen bundles remained intact and no necrotic inflammation was apparent (Fig 5, A-C). Tumor cells were evident at the injection site for $\sim 7$ days after vaccination, and little evidence of their presence was found after 14 days (Fig 5D). Representative examples for all experimental groups are illustrated. In an effort to objectively measure the differences between sites, the greatest area of inflammatory or liquifactive necrosis was calculated through microscopy and summarized for the first study of day 7 biopsy samples (Tables 1 and 2). This method was used because an accurate assessment and counting of intact cell populations was difficult in hGM-CSF-transfected tumor cell vaccine sites by day 7. Overall, tumor vaccine injections and transfected cell doses were well tolerated; all clinical assessments were within normal limits.

In vivo hGM-CSF protein production at sites of vaccination

To evaluate in vivo hGM-CSF production levels at sites of vaccination, skin punch biopsy samples were collected with $8-\mathrm{mm}$ punches and split in half for analysis. ELISAs demonstrated ranges of 8.68-16.82 $\mathrm{ng}$ and a mean concentration of $12.58 \mathrm{ng}$ of hGM-CSF/million cells/24 hours in vivo at sites of injection (Tables 3 and 4). These concentrations decreased to a mean of $0.21 \mathrm{ng}$ by day 7 and $0.01 \mathrm{ng}$ by day 28 , reflecting the transient transfection induced by the Accell transfer method. However, the hGM-CSF cDNA 3' alterations confer significantly greater, and longer lasting, expression than does standard hGM-CSF or a simple injection of protein prod- uct. $^{60,72}$ No hGM-CSF was detected in any sera samples collected in animals at any of the indicated timepoints. These ranges and the duration of expression observed in the research dogs are actually preferred for immunological effects rather than hematopoietic effects of GM-CSF. $^{73}$

\section{DISCUSSION}

Using an established canine melanoma cell line in normal dogs, we have demonstrated that an irradiated, hGM-CSF cytokine-gene-engineered melanoma cell vaccine, incapable of cell proliferation, was able to produce hGM-CSF at the site of injection for an extended period and was clinically well tolerated. Using the Accell gene transfer device, we determined optimal gene transfer conditions for hGM-CSF cDNA into canine melanoma cell lines and demonstrated that these cytokine-gene-modified cells can produce a functional protein product. Although transfection and protein expression are transient using this method of gene transfer, we have shown biologically relevant levels of cytokines in vivo at the sites of vaccination with irradiated, transfected tumor cells.

Cell viability and proliferation assays demonstrated that previously published and accepted levels of irradiation induce reproductive cell death in canine cells, without any inhibitory effects on the synthesis of the hGM-CSF protein product, both in vitro and in vivo. ${ }^{1}$ Therefore, the irradiation of tumor cell lines seems to have a negligible effect on cytokine production, and has been reported by some investigators to actually increase total protein production over time. 7 These assays address a major concern with any tumor vaccine protocol: 


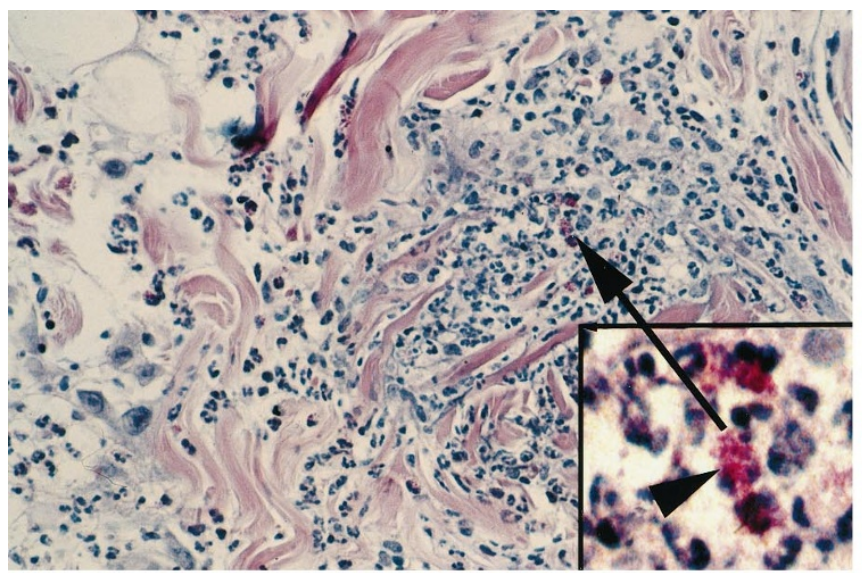

A.

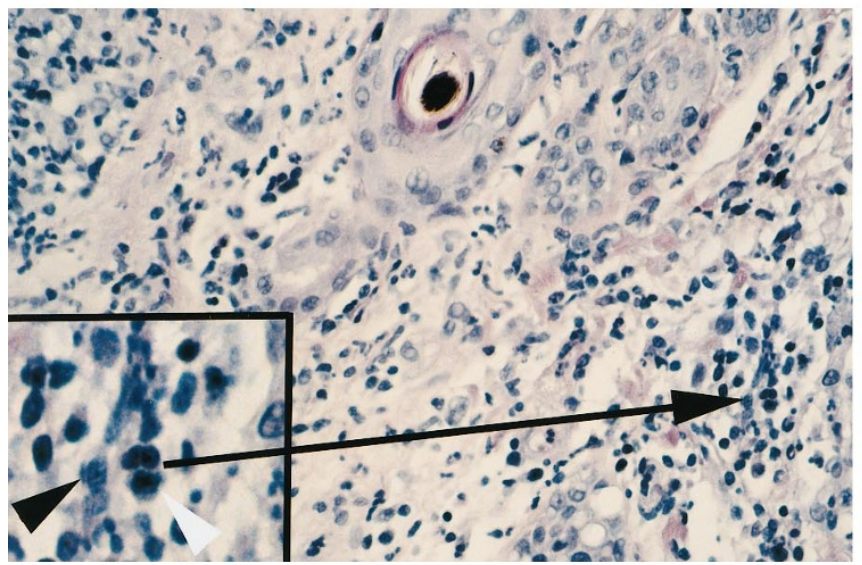

B.

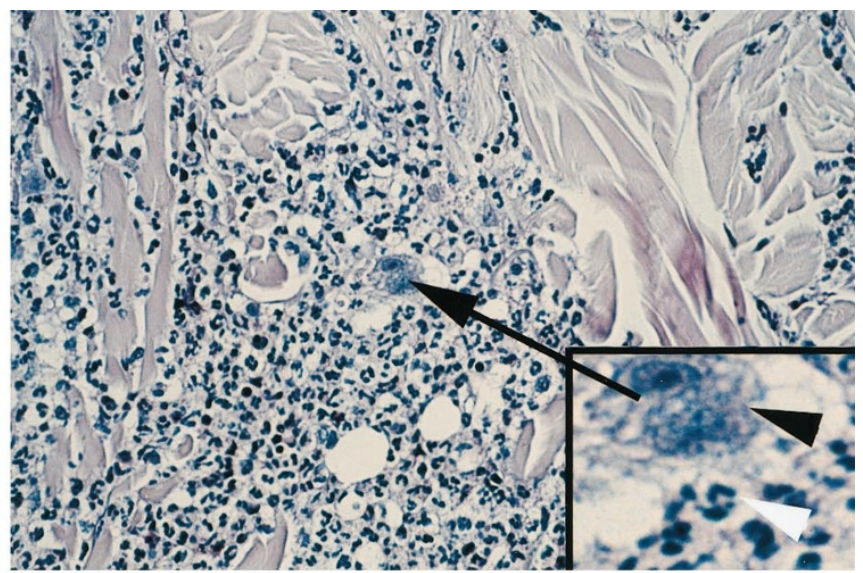

C.

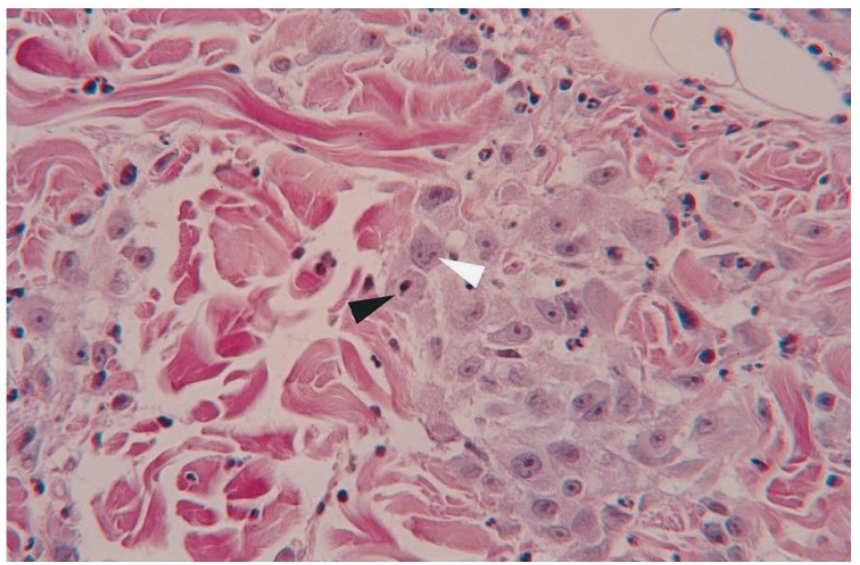

D.

Figure 5. Histopathology of sites of vaccination. Cells $\left(10^{7}\right)$ were administered i.d. and biopsied on days 1,7 , and 28 . Representative sections are presented. Similar results were observed for both $\beta$-gal-transfected controls and for nontransfected control samples. A: $\times 250$ magnification of a control nontransfected, irradiated tumor cell site biopsy at 7 days after injection. The insert is a higher magnification of the eosinophils obtained from the indicated area, and the arrowhead points to an eosinophil, B: Day 7 hGM-CSF-transfected tumor cell vaccination site biopsy at $\times 250$ magnification. The insert is a higher magnification of $\mathrm{M} \phi$ (black arrowhead) and lymphocytes (white arrowhead). C: Day 7 hGM-CSF-transfected tumor cell vaccination site biopsy at $\times 250$ magnification. The insert is a higher magnification of an intact tumor cell (black arrowhead) and neutrophils (white arrowhead). D: Day 1 irradiated, hGM-CSF-transfected tumor cells at the site of injection $(\times 400$ magnification). Darkly basophilic staining cells are the tumor cells. The white arrowhead points to an intact tumor cell, and the black arrowhead demonstrates a representative gold bead that seems to be associated with the nucleus of the injected tumor cell.

the induction of reproductively viable tumor cells into a vaccine site.

hGM-CSF vaccine injection sites grossly differed from control sites in the degree of inflammation and in the appearance of eschar at the injection areas. Controltransfected or nontransfected irradiated tumor cells had noticeably less inflammation at 24 hours after injection than did the hGM-CSF vaccine sites, and it was difficult to discern these control sites 7 days after the injection of cells.

Our most exciting results in this preclinical study were the obvious differences in inflammatory responses and the presence of follicular atrophy observed between animals in the first in vivo experiment and between treatment sites in the second in vivo experiment. Neutrophils, lymphocytes, and $\mathrm{M} \phi$ dominated the inflamma-

Table 1. Experiment 1, Day 7, Low-Magnification Measurements of the Diameters of Greatest Inflammatory or Liquifactive Necrosis in Millimeters

\begin{tabular}{ccccc}
\hline Day 7 & No. $2890(\mathrm{C})$ & No. $2892(\mathrm{C})$ & No. $2894(\mathrm{Tx})$ & No. $2892(\mathrm{Tx})$ \\
\hline $.094 \mathrm{~mm}$ & $0 \mathrm{~mm}$ & $1.50 \mathrm{~mm}$ & $1.03 \mathrm{~mm}$ \\
\hline
\end{tabular}

Samples were read single-blinded by a veterinary pathologist (R.R.D.). C, control; Tx, hGM-CSF-transfected sample. 
Table 2. Experiment 2, Day 7, Low-Magnification Measurements of the Diameters of Greatest Inflammatory or Liquifactive Necrosis in Millimeters

\begin{tabular}{crcc}
\hline \multicolumn{1}{c}{ Day 7} & No. 2133 & No. 2914 & No. 2916* \\
\hline Control sites & $0 \mathrm{~mm}$ & $0.10 \mathrm{~mm}$ & $0 \mathrm{~mm}$ \\
GM-CSF sites & $2.00 \mathrm{~mm}$ & $1.00 \mathrm{~mm}$ & $0 \mathrm{~mm}$ \\
\hline
\end{tabular}

*Original vaccination site could not be visually determined; sample was taken from approximate area of vaccination.

tory response seen at hGM-CSF sites, which contrasted sharply with the control $\beta$-gal-transfected or nontransfected irradiated melanoma tumor cell injection sites. This was true for both numbers of inflammatory cells and in the induction of diffuse necrotic inflammation. Sites injected with $\beta$-gal-transfected or nontransfected tumor cells had similar histological appearances in vivo following vaccination. Our results are consistent with the findings of several other groups using GM-CSF transfection, including Dranoff et al, ${ }^{1}$ Mahvi et al, ${ }^{7}$ Rajagopalan et al, ${ }^{61}$ and Wakimoto et al. ${ }^{74}$ These authors found minimal infiltration at sites of control tumor cell vaccination, whereas significant lymphocyte and $\mathrm{M} \phi$ infiltration was observed at sites of hGM-CSF-transfected tumor cell administration.

The disruption of collagen bundles and generalized necrotic inflammatory processes that we observed were likely attributable to the release of protease-containing granules from the infiltrating neutrophils and $\mathrm{M} \phi$. This effect was not observed in the control sites, because the numbers of neutrophils were much less than at the hGM-CSF sites. Furthermore, we hypothesize that the predominant eosinophilic response at control sites may be a reflection of the typical inflammatory response, where eosinophils and other polymorphonuclear cells are among the first cells to respond to an irritant. Without the driving force of a $\mathrm{T}$ helper 1 cytokine (in our case hGM-CSF) to bring in additional polymorphonuclear cells, only moderate levels of inflammatory cells are present and a $\mathrm{T}$ helper 2 response may exist. The acute inflammatory response at the hGM-CSF sites may be overwhelmed by other cell types, such as lymphocytes and $\mathrm{M} \phi$, and the initial responding population may eventually be disrupted in the necrotic inflammation observed.

The protein expression levels in vivo that were obtained by ELISA analysis of punch biopsy samples at the sites of injection showed biologically relevant levels of hGM-CSF at 24 hours after injection. Because protein production is a cumulative process by intact, transfected tumor cells with viable mRNA generation, we believe
Table 4. Experiment 2, hGM-CSF Expression In Vivo at Sites of Vaccination on the Right Thoracic Flanks in Nanograms Per Site Per Indicated Time*

\begin{tabular}{lrrl}
\hline & No. 2133 & No. 2914 & No. 2916 \\
\hline Day 1 & $13.42 \mathrm{ng}$ & $11.53 \mathrm{ng}$ & $8.68 \mathrm{ng}$ \\
Day 7 & $.274 \mathrm{ng}$ & $.202 \mathrm{ng}$ & $0.08 \mathrm{ng}$ \\
Day 21 & $.081 \mathrm{ng}$ & $.048 \mathrm{ng}$ & $.041 \mathrm{ng}$ \\
\hline
\end{tabular}

*Control tumor cell vaccine injection site biopsy samples, from left flanks of the dogs, were negative for hGM-CSF for all timepoints.

†Original vaccination site could not be visually determined; sample was taken from approximate area of vaccination instead.

that our system is capable of generating the desired immunologically effective dose of GM-CSF of 24-48 $\mathrm{ng} / 10^{6}$ cells, as determined in preclinical studies by Berns et al. ${ }^{73}$ The intermediate dose effect eliciting the greatest host antitumor immunity was also observed by Abe et al. ${ }^{50}$

No toxicity was observed in any animals using our dose injection level of $10^{7}$ cells/site. The i.d. vaccine injection sites were well tolerated by the dogs, and the mild pruritus did not result in any gross lesions that were attributable to excessive scratching or biting of the sites. No alterations in blood or chemistry values were seen, and all subjective behavioral observations (appetite, water consumption, sleep patterns, etc.) were within normal limits. Furthermore, no hGM-CSF was detected in sera at any timepoint.

We believe that the study of hGM-CSF-transfected tumor cell vaccines in dogs provides a valuable translational research model. GM-CSF-transfected cells have been shown in numerous studies to have potent antineoplastic effects, albeit in an indirect manner. However, by increasing the numbers and life spans of critical inflammatory cells, and through the enhancement of host $\mathrm{Ag}$ presentation function, deficits in Ag presentation and a costimulation of tumor cells may be overcome. Our research group has previously demonstrated the potent inflammatory and immunological effects of hGM-CSF in the dog model. ${ }^{27,51}$

The Accell device provides a useful method of gene transfer, eliminating the extended cell culture manipulations that were required previously to generate a biologically active, nontoxic, well-tolerated tumor cell vaccine. Our use of control-transfected or nontransfected tumor cells also addresses many concerns regarding the natural immunogenicity of many tumor cell vaccine studies previously conducted in murine models. ${ }^{75,76}$ As a result, we have initiated a phase I clinical

Table 3. Experiment 1, hGM-CSF Expression In Vivo at Sites of Vaccination in Nanograms Per Site Per Indicated Time

\begin{tabular}{lcccc}
\hline & No. 2890 (C) & No. 2889 (C) & No. 2894 (Tx) & No. 2892 (Tx) \\
\hline Day 1 & $.010 \mathrm{ng}$ & $.010 \mathrm{ng}$ & $16.82 \mathrm{ng}$ & $12.53 \mathrm{ng}$ \\
Day 7 & $.010 \mathrm{ng}$ & $.010 \mathrm{ng}$ & $.179 \mathrm{ng}$ & $.174 \mathrm{ng}$ \\
Day 28 & $.010 \mathrm{ng}$ & $.010 \mathrm{ng}$ & $.014 \mathrm{ng}$ & $.014 \mathrm{ng}$ \\
\hline
\end{tabular}

C, control; Tx, hGM-CSF-transfected sample. 
trial using hGM-CSF-transfected, irradiated, autologous tumor cells in dogs with spontaneous melanoma and soft tissue sarcomas.

\section{ACKNOWLEDGMENTS}

We thank Ilene Kurzman and William Swain for their valuable proofreading and scientific input, Kathy Schell for flow cytometry expertise, and Shelley Humphrey for technical assistance and animal work. This work was supported in part by the University of Wisconsin-Madison School of Veterinary Medicine Companion Animal Fund.

\section{REFERENCES}

1. Dranoff G, Jaffe E, Lazenby A, et al. Vaccination with irradiated tumor cells engineered to secrete murine granulocyte-macrophage colony-stimulating factor stimulates potent, specific, and long-lasting anti-tumor immunity. Proc Natl Acad Sci USA. 1993;90:3539-3543.

2. Ezzell C. Cancer "vaccines": an idea whose time has come? J NIH Res. 1995;7:46-49.

3. Pardoll DM. Paracrine cytokine adjuvants in cancer immunotherapy. Annu Rev Immunol. 1995;13:399-415.

4. Rosenthal FM, Cronin K, Bannerji R, et al. Augmentation of antitumor immunity by tumor cells transduced with retroviral vector carrying the interleukin-2 and interferon- $\gamma$ cDNAs. Am Soc Hematol. 1994;83:1289-1298.

5. Simons JW, Jaffe EM, Weber CE, et al. Bioactivity of autologous irradiated renal cell carcinoma vaccines generated by ex vivo granulocyte-macrophage colony-stimulating factor gene transfer. Cancer Res. 1997;57:1537-1546.

6. Vieweg J, Gilboa E. Considerations for the use of cytokine-secreting tumor cell populations for cancer treatment. Cancer Invest. 1995;13:193-201.

7. Mahvi DM, Burkholder JK, Turner J, et al. Particlemediated gene transfer of GM-CSF cDNA to tumor cells: implications for a clinically relevant tumor vaccine. Hum Gene Ther. 1996;7:1535-1543.

8. Saito S, Bannerji R, Gansbacher B, et al. Immunotherapy of bladder cancer with cytokine gene-modified tumor vaccines. Cancer Res. 1994;54:3516-3520.

9. Irvine KR, Rao JB, Rosenberg SA, et al. Cytokine enhancement of DNA immunization leads to effective treatment of established pulmonary metastasis. J Immunol. 1996;156:229-245.

10. Chamberlain RS, Carroll MW, Bronte V, et al. Costimulation enhances the active immunotherapy effect of recombinant anticancer vaccines. Cancer Res. 1996;56:28322836.

11. Hodge JW, McLaughlin JP, Abrams SI, et al. Admixture of recombinant vaccinia virus containing the gene for the costimulatory molecule B7 and recombinant vaccinia virus containing a tumor-associated antigen results in enhanced specific T-cell responses and antitumor immunity. Cancer Res. 1995;55:3598-3603.

12. Fleischmann JD, Shingleton WB, Gallagher C. Fibrinolysis, thrombocytopenia, and coagulation abnormalities complicating high-dose interleukin-2 immunotherapy. J Lab Clin Med. 1991;117:76-82.

13. Wong L, Taylor CW, Radwanski E, et al. Comparison of 4and 24-hour intravenous infusion schedules for granulo- cyte-macrophage colony-stimulating factor. J Immunother Emphasis Tumor Immunol. 1995;18:57-65.

14. Rosenberg SA, Packard BS, Aerbersold PM, et al. Use of tumor-infiltrating lymphocytes and interleukin-2 in the immunotherapy of patients with metastatic melanoma. N Engl J Med. 1988;319:1676-1680.

15. Lotze M, Matory Y, Rayner A, et al. Clinical effects and toxicity of interleukin-2 in patients with cancer. Cancer. 1986;58:2764-2772.

16. Lotze MT. Cytokine gene therapy of Cancer. Cancer J Sci Am. 1996;2:63-72.

17. Gilboa E, Lyerly HK, Vieweg J, et al. Immunotherapy of cancer using cytokine gene-modified tumor vaccines. Semin Cancer Biol. 1994;5:409-417.

18. Gilboa E. Immunotherapy of cancer with genetically modified tumor vaccines. Semin Oncol. 1996;23:101-107.

19. Miller AR, McBride WH, Hunt K, et al. Cytokine-mediated gene therapy for cancer. Ann Surg Oncol. 1994;1:436450.

20. Thompson TA, Gould MN, Burkholder J, et al. Transient promoter activity in primary rat mammary epithelial cells evaluated using particle bombardment gene transfer. In Vitro Cell Dev Biol. 1993;29:165-170.

21. Burkholder JK, Decker J, Yang N-S. Rapid transgene expression in lymphocyte and macrophage primary cultures after particle bombardment-mediated gene transfer. J Immunol Methods. 1993;165:149-156.

22. Yang N-S, Burkholder J, Roberts B, et al. In vivo and in vitro gene transfer to mammalian somatic cells by particle bombardment. Proc Natl Acad Sci USA. 1990;87:95689572.

23. Yang N-S. Gene transfer into mammalian somatic cells in vivo. In: CRC Critical Reviews in Biotechnology. Toronto, Canada: CRC Press; 1992:335-356.

24. Yang N-S, Jiao S, DeLuna C. Particle bombardment for gene transfer into nerve cell systems. In: Flanagan TR, ed. Providing Pharmaceutical Access to the Brain. San Diego: Academic Press; 1994:427-440.

25. Eisenbraun MD, Fuller DH, Haynes JR. Examination of parameters affecting the elicitation of humoral immune responses by particle bombardment-mediated genetic immunization. DNA Cell Biol. 1993;12:791-797.

26. Cheng L, Ziegelhoffer PR, Yang N-S. In vivo promoter activity and transgene expression in mammalian somatic tissues evaluated using particle bombardment. Proc Natl Acad Sci USA. 1993;90:4455-4459.

27. Keller ET, Burkholder JK, Shi F, et al. In vivo particlemediated cytokine gene transfer into canine oral mucosa and epidermis. Cancer Gene Ther. 1996;3:186-191.

28. Sun WH, Burkholder JK, Sun J, et al. In vivo cytokine gene transfer by gene gun suppresses tumor growth in mice. Proc Natl Acad Sci USA. 1995;92:2889-2893.

29. Rakhmilevich AL, Turner J, Ford MJ, et al. Gene gunmediated skin transfection with interleukin-12 gene results in regression of established primary and metastatic murine tumors. Proc Natl Acad Sci USA. 1996;93:6291-6296.

30. Jiao S, Cheng L, Wolff JA, et al. Particle bombardmentmediated gene transfer and expression in rat brain tissues. Biotechnology. 1993;11:497-501.

31. Albertini MR, Emler CA, Schell K, et al. Dual expression of human leukocyte antigen molecules and the B7-1 costimulatory molecule (CD80) on human melanoma cells after particle-mediated gene transfer. Cancer Gene Ther. 1996;3:192-201.

32. Zarozinski CC, Fynan EF, Selin LK, et al. Protective 
CTL-dependent immunity and enhanced immunopathology in mice immunized by particle bombardment with DNA encoding an internal virion protein. $J$ Immunol. 1995;154:4010-4017.

33. Tang D-C, DeVit M, Johnston SA. Genetic immunization is a simple method for eliciting an immune response. Nature. 1992;356:152-154.

34. Fynan EF, Webster RG, Fuller DH, et al. DNA vaccines: protective immunizations by parenteral, mucosal, and gene-gun inoculations. Proc Natl Acad Sci USA. 1993;90: $11478-11482$.

35. Feltquate DM, Heaney S, Webster RG, et al. Different Th cell types and antibody isotypes generated by saline and gene gun DNA immunizations. J Immunol. 1997;158: 2278-2284.

36. Haynes JR, McCabe DE, Swain WF, et al. Particlemediated nucleic acid immunization. J Biotechnol. 1995;44: 37-42.

37. Haynes JR, Fuller DH, McCabe D, et al. Induction and characterization of humoral and cellular immune responses elicited via gene gun-mediated nucleic acid immunization. Adv Drug Deliv Rev. 1996;21:3-18.

38. Gasson JC. Molecular physiology of granulocyte-macrophage colony-stimulating factor. Blood. 1991;77:1131-1145.

39. Rasko J, Gough N. GM-CSF. In: Thompson A, ed. Cytokine Handbook. New York: Academic Press; 1996: 343-369.

40. Hill ADK, Naama HA, Calvano SE, et al. The effect of granulocyte-macrophage colony-stimulating factor on myeloid cells and its clinical applications. J Leukoc Biol. 1995;58:634-642.

41. Groopman JE, Molina J-M, Scadden DT. Hematopoietic growth factors: biology and clinical applications. $N$ Engl J Med. 1989;321:1449-1459.

42. Vose JM, Armitage JO. Clinical applications of hematopoietic growth factors. J Clin Oncol. 1995;13:1023-1035.

43. Mui A, Muto A, Sakamaki K, et al. 1994. Function of the common $\beta$ subunit of the GM-CSF/IL-3/IL-5 receptors. Mech Lymphocyte Activ Immunol Reg. 1994;V:217-223.

44. Chachoua A, Oratz R, Hoogmoed R, et al. Monocyte activation following systemic administration of granulocyte-macrophage colony-stimulating factor. J Immunother. 1994;15:217-224.

45. Cebon JS, Lieschke GJ. Granulocyte-macrophage colonystimulating factor for cancer treatment. Oncology. 1994;51: 177-188.

46. Boczkowski D, Nair SK, Snyder D, et al. Dendritic cells pulsed with RNA are potent antigen-presenting cells in vitro and in vivo. $J$ Exp Med. 1996;184:465-472.

47. Grabbe S, Beissert S, Schwarz T, et al. Dendritic cells as initiators of tumor immune responses: a possible strategy for tumor immunotherapy. Immunol Today. 1995;16:117121.

48. Porgador A, Snyder D, Gilboa E. Induction of antitumor immunity using bone marrow-generated dendritic cells. J Immunol. 1996;156:2918-2926.

49. Arca MJ, Krauss JC, Strome SE, et al. Diverse manifestations of tumorigenicity and immunogenicity displayed by the poorly immunogenic B16-BL6 melanoma transduced with cytokine genes. Cancer Immunol Immunother. 1996; 42:237-245.

50. Abe J, Wakimoto H, Yoshida Y, et al. Antitumor effect induced by granulocyte-macrophage colony-stimulating factor gene-modified tumor vaccination: comparison of adenovirus- and retrovirus-mediated genetic transduction. J Cancer Res Clin Oncol. 1995;121:587-592.
51. Kurzman ID, MacEwen EG, Broderick C, et al. Effect of colony-stimulating factors on number and function of circulating monocytes in normal dogs. Mol Biother. 1992; 4:29-33.

52. MacEwen EG, Patnaik AK, Harvey HJ, et al. Canine oral melanoma: comparison of surgery versus surgery plus Corynebacterium parvum. Cancer Invest. 1986;4:397-402.

53. Vail DM, Withrow SJ. Tumors of the skin and subcutaneous tissues. In: Withrow SJ, MacEwen EG, eds. Small Animal Clinical Oncology. Philadelphia: W. B. Saunders; 1996:183-191.

54. Bostock DE. Prognosis after surgical excision of canine melanomas. Vet Pathol. 1979;16:32-40.

55. Dorn CR, Taylor D, Schneider R, et al. Survey of animal neoplasms in Alameda and Contra Costa counties: cancer morbidity in dogs and cats from Alameda county. $J$ Natl Cancer Inst. 1968;40:307-318.

56. Birchard S. Surgical management of neoplasms of the oral cavity in dogs and cats. In: C. G. Couto, ed. The 20th Annual Waltham/OSU Symposium for the Treatment of Small Animal Diseases. Oncology and Hematology; Vol 20. Columbus, Ohio: Waltham USA; 1996:51-58.

57. Blackwood L, Dobson JM. Radiotherapy of oral malignant melanomas in dogs. J Am Vet Med Assoc. 1996;209:98-102.

58. Todoroff RJ, Brodey RS. Oral and pharyngeal neoplasia in the dog: a retrospective survey of 361 cases. J Am Vet Med Assoc. 1979;175:567-571.

59. MacEwen EG. Spontaneous tumors in dogs and cats: models for the study of cancer biology and treatment. Cancer Metastasis Rev. 1990;9:125-136.

60. Vail DM, MacEwen EG. Spontaneously occurring tumors in companion animals as models for drug development. In: Teicher B, ed. Anticancer Drug Development Guide: Preclinical Screening, Clinical Trials, and Approval. Totowa, NJ: Humana Press; 1997:197-211.

61. Rajagopalan LE, Burkholder JK, Turner J, et al. Granulocyte-macrophage colony-stimulating factor mRNA stabilization enhances transgenic expression in normal cells and tissues. Blood. 1995;86:2551-2558.

62. Cotten M, Baker A, Saltik M, et al. Lipopolysaccharide is a frequent contaminant of plasmid DNA preparations and can be toxic to primary human cells in the presence of adenovirus. Gene Ther. 1994;1:239-246.

63. Pertmer TM, Eisenbraun MD, McCabe D, et al. Gene gun-based nucleic acid immunization: elicitation of humoral and cytotoxic $\mathrm{T}$ lymphocyte responses following epidermal delivery of nanogram quantities of DNA. Vaccine. 1995; 13:1427-1430.

64. Wolfe LG, Oliver JL, Smith BB, et al. Biological characterization of canine melanoma cell lines. Am J Vet Res. 48:1642-1648.

65. Pardee AB. A restriction point for control of normal animal cell proliferation. Proc Natl Acad Sci USA. 1974;1: 1286-1290.

66. Temin HM. Stimulation by serum of multiplication of stationary chicken cells. J Cell Phys. 1971;78:161-170.

67. Berridge MV, Tan AS, McCoy KD, et al. The biochemical and cellular basis of cell proliferation assays that use tetrazolium salts. Biochemica. 1996;4:14-19.

68. Vistica DT, Skehan P, Scudiero D, et al. Tetrazoliumbased assays for cellular viability: a critical examination of selected parameters affecting formazan production. Cancer Res. 1991;51:2515-2520.

69. Hall EJ. Cell survival curves. In: Radiobiology for the Radiologist. Philadelphia: J. B. Lippincott; 1994:29-44. 
70. Yang N-S, DeLuna C, Cheng L. Gene transfer via particle bombardment: applications of the Accell gene gun. In: Wolff J, ed. Gene Pharmaceutics. Boston: Birkhäuser; 1994:193-209.

71. Yang N-S, Ziegelhoffer PR. The particle bombardment system for gene transfer. In: Yang N-S, Christou P, eds. Particle Bombardment Technology for Gene Transfer. New York: Oxford University Press; 1994:117-142.

72. Rajagopalan LE, Malter JS. Modulation of granulocytemacrophage colony-stimulating factor mRNA stability in vitro by the adenosine-uridine binding factor. J Biol Chem. 1994;269:23882-23888.

73. Berns AJM, Clift S, Cohen LK, et al. Phase I study of non-replicating autologous tumor cell injections using cells prepared with or without GM-CSF transduction in pa- tients with metastatic renal cell carcinoma: clinical proto col. Hum Gene Ther. 1995;6:347-368.

74. Wakimoto H, Abe J, Tsunoda R, et al. Intensified antitumor immunity by a cancer vaccine that produces granulocyte-macrophage colony-stimulating factor plus interleukin-4. Cancer Res. 1996;56:1828-1833.

75. Jaffe EM, Lazenby A, Meurer J, et al. Use of murine models of cytokine-secreting tumor vaccines to study feasibility and toxicity issues critical to designing clinical trials. J Immunother. 1995;18:1-9.

76. Columbo MP, Rodolfo M. Tumor cells engineered to produce cytokines or cofactors as cellular vaccines: do animal studies really support clinical trials? Cancer Immunol Immunother. 1995;41:265-270. 